\title{
Q fever: A neglected disease of camels in Giza and Cairo Provinces, Egypt
}

\author{
Hend H. A. M. Abdullah ${ }^{1}$, Hany A. Hussein ${ }^{2,3}$, Khaled A. Abd El-Razik², Ashraf M. A. Barakat ${ }^{4}$ and Yousef A. Soliman ${ }^{5}$ \\ 1. Department of Parasitology and Animal Diseases, National Research Centre, Dokki, Giza, Egypt; 2. Department of \\ Animal Reproduction and Artificial Insemination, National Research Centre, Dokki, Giza, Egypt; 3. Key Laboratory of \\ Diagnostic and Detective Technology, Department of Veterinary Research, Guangdong Haid Institute of Animal Husbandry \\ and Veterinary, Guangzhou, China; 4. Department of Zoonotic Diseases, National Research Centre, Dokki, Giza, Egypt; \\ 5. Department of Biotechnology, Central Laboratory for Evaluation of Veterinary Biologics, Abbasia, Cairo, Egypt. \\ Corresponding author: Hend H. A. M. Abdullah, e-mail: vet nrc 2006@yahoo.com \\ Co-authors: HAH: hnyhussein2@yahoo.com, KAA: khaled707@hotmail.com, AMAB: ashrafbarakat2@hotmail.com, \\ YAS: yousefadel00@hotmail.com \\ Received: 06-09-2019, Accepted: 06-11-2019, Published online: 12-12-2019 \\ doi: www.doi.org/10.14202/vetworld.2019.1945-1950 How to cite this article: Abdullah HHAM, Hussein HA, \\ Abd El-Razik KA, Barakat AMA, Soliman YA (2019) Q fever: A neglected disease of camels in Giza and Cairo Provinces, \\ Egypt, Veterinary World, 12(12): 1945-1950.
}

\begin{abstract}
Background and Aim: Q fever is a zoonotic disease caused by Coxiella burnetii. Cattle, sheep, and goat are the main reservoir of $C$. burnetii. In Egypt, the epidemiological data about $C$. burnetii in camels are limited. Therefore, the current study was conducted to identify $C$. burnetii infection in camels by different molecular tools and to estimate its seropositivity through the detection of anti-C. burnetii antibodies in camel sera.
\end{abstract}

Materials and Methods: Blood samples were collected 112 from camels in Giza and Cairo Provinces, Egypt. All blood samples were screened by trans-quantitative polymerase chain reaction (trans-qPCR) for C. burnetii and positive samples subjected to standard PCR using the superoxide dismutase enzyme coding gene of $C$. burnetii. Sera of studied camels were examined for the presence of antibodies against $C$. burnetii using enzyme-linked immunosorbent assay.

Results: Out of 112 camels, 19 were positive for C. burnetii by qPCR with an overall prevalence of $16.9 \%$ (18.6\% in Giza and $15.1 \%$ in Cairo Provinces, respectively). The seroprevalence of anti-C. burnetii IgG antibodies in the examined camels was $4.5 \%(5 / 112)$.

Conclusion: Trans-qPCR assay is a rapid and sensitive tool for the detection of $C$. burnetii in acute stage. Camels should be considered one of the major reservoirs for C. burnetii in Egypt.

Keywords: camel, Coxiella burnetii, enzyme-linked immunosorbent assay, standard polymerase chain reaction, transquantitative polymerase chain reaction.

\section{Introduction}

Q fever is an acute, highly contagious zoonotic disease that is commonly neglected [1]. It is caused by Coxiella burnetii, a strict intracellular Gram-negative bacterium [2]. C. burnetii has been classified by Centers for Disease Control and Prevention as a potential bioterrorism agent [3]. The organism can infect a wide variety of animals, human, birds, and arthropods; however, ruminants act as the main reservoir [1]. Q fever infection in animals is mostly clinically inapparent; nonetheless, abortion, stillbirth, decrease in the reproduction efficiency, and infertility are all reported [4]. In human, the acute C. burnetii infection is characterized by fever, flu-like signs, headache, and pneumonia, whereas hepatitis and endocarditis are serious complications in chronic cases [5]. Infected mammals

Copyright: Abdullah, et al. Open Access. This article is distributed under the terms of the Creative Commons Attribution 4.0 International License (http://creativecommons.org/licenses/ by/4.0/), which permits unrestricted use, distribution, and reproduction in any medium, provided you give appropriate credit to the original author(s) and the source, provide a link to the Creative Commons license, and indicate if changes were made. The Creative Commons Public Domain Dedication waiver (http:// creativecommons.org/publicdomain/zero/1.0/) applies to the data made available in this article, unless otherwise stated. shed C. burnetii in their urine, feces, milk, and birth products [6-8]. Infection can spread both vertically and horizontally, through contact with bodily fluids or transmission through arthropod vectors [6,9].

In dromedary camels, the seroprevalence of C. burnetii is reported to range from $0 \%$ to $80 \%$ [10]. Two studies from Kenya showed different percentages of infected camels; $46 \%$ and $18.6 \%$ [11,12]. Research work from other countries showed comparable results; $28 \%$ in Iran [13,14], 51.6\% in Saudi Arabia [15], and $19 \%$ in Spain [16]. A recently conducted study in Saudi Arabia highlighted the emergence of $C$. burnetii as a possible cause of uterine infection in dromedary camels [17]. In Egypt, studies concerned with seroprevalence of C. burnettii in camels are few. It was diagnosed in 13\% of examined animals by immunofluorescence assay (IFA) [18], while using enzyme-linked immunosorbent assay (ELISA), infection was confirmed in $71 \%, 70 \%$ and $40.7 \%$ of examined animals; respectively $[19,20,21]$. Likewise, through molecular tools, C. burnettii DNA was diagnosed in $46 \%$ of blood samples of examined animals by polymerase chain reaction (PCR) [22].

The isolation of $C$. burnetii is the gold standard for diagnosis of $\mathrm{Q}$ fever; however, it is 
time-consuming and hazardous [23,24]. Due to the absence of characteristic signs for $Q$ fever besides the subclinical and asymptomatic nature in most cases, the seroprevalence studies could be used to indicate exposure and chronicity of infection rather than to detect organism [25]. Detection of antibodies against C. burnetii is usually done by ELISA, IFA, or complement fixation test. Due to its higher sensitivity among other practical reasons, ELISA is mostly preferred $[26,27]$.

Molecular-based methods are numerous, and they include nested PCR assay $[18,28]$, real-time PCR [29], touch-down PCR [30], and trans-PCR targeting IS1111, the repetitive transposon-like region of C. burnetii [31]. These methods have recently emerged as valuable diagnostic tools, and they can be utilized to study the incidence and prevalence of Q fever and help in understanding its epidemiology.

In Egypt, studies concerned with seroprevalence of $C$. burnetii in dromedary camels are few, and we have no much information regarding its epidemiological status. Therefore, this study was designed to screen for $C$. burnetii infection in camels using quantitative PCR (qPCR) and conventional PCR and to estimate its seropositivity through the detection of anti-C. burnetii antibodies using ELISA technique.

\section{Materials and Methods}

\section{Ethical approval}

This study obtained approval from the Ethics Committee of the National Research Centre. Throughout the study, all procedures were carried out in compliance with the Guide for the Care and Use of Laboratory Animals published by the US National Institutes of Health.

\section{Study design and animals}

We conducted a cross-sectional study and included a total of 112 male camels using a convenience sampling strategy. Blood samples were collected from 60 camels at Police Academy and 52 at slaughterhouses in Giza and Cairo Provinces, Egypt. Each camel was subjected to data recording (including disease history, clinical signs, age, breed, and tick infestation) besides molecular and serological screening for $C$. burnetii infection.

\section{Sampling}

We collected blood either from jugular veins of animals at Police Academy or from the cut jugular veins or carotid arteries immediately after slaughter at the slaughterhouses. From each animal, two blood samples $(5 \mathrm{ml}$ each) were collected. For molecular studies, ethylenediaminetetraacetic acid-containing Vacutainer tubes were used. For seroepidemiology examination, we used plain Vacutainer tubes to collect samples that were left at room temperature for $12 \mathrm{~h}$ to allow clotting and sera separation. The collected anticoagulated whole blood and serum samples were kept at $-20^{\circ} \mathrm{C}$ till used.

\section{Molecular studies}

\section{DNA extraction}

We extracted that DNA from the collected whole blood samples was using GF-1 Tissue Blood Combi DNA Extraction Kit (SNF, Vivantis, Malaysia) according to the manufacturer's instructions. The extracted DNA was stored at $-20^{\circ} \mathrm{C}$ till used.

\section{Detection of $C$. burnetii in different samples using SYBR Green real-time PCR}

We screened all samples for $C$. burnetii DNA by qPCR using specific primer derived from a transposon-like repetitive region of the $C$. burnetii genome; Trans1 and Trans2 (Table-1) [25]. Briefly, real-time PCR was performed in a final volume of $20 \mu \mathrm{l}$, using the $2 \times$ QuantiNova $^{\circledR}$ SYBR $^{\circledR}$ Green PCR Master Mix (Cat. no. 208052, Qiagen), 50 pmol of each primer, and $5 \mu \mathrm{l}$ of extracted DNA. Amplification was carried out in a Stratagene Mx3000P (Agilent Technologies). The cycling profiles were holding step at $95^{\circ} \mathrm{C}$ for $3 \mathrm{~min}, 35$ cycles of $95^{\circ} \mathrm{C}$ for $30 \mathrm{~s}, 62^{\circ} \mathrm{C}$ for $30 \mathrm{~s}$, and $60^{\circ} \mathrm{C}$ for $30 \mathrm{~s}$. A single fluorescence reading for each sample was taken at the extension step. Results were expressed by the determination of the cycle threshold, which marked the cycle when the fluorescence of a given sample significantly exceeded the baseline signal. The melting step was set as default in the machine.

\section{Detection of C. burnetii in different samples using conventional PCR}

We subjected all qPCR-positive samples to standard PCR and sequencing. CB1 and CB2 primers were used targeting $257 \mathrm{bp}$ of the superoxide dismutase enzyme coding gene of C. burnetii (Table-1) [32]. All PCR amplifications were performed on BIO-RAD Thermal Cycler (BIO-RAD, Singapore) using $2 \times$ PCR Master Mix solution (i-Taq, Intron) according to the manufacturer's recommendation. The protocol of PCR reactions was performed as the following: initial denaturation at $94^{\circ} \mathrm{C}$ for $5 \mathrm{~min}$ and 35 cycles of denaturation at $94^{\circ} \mathrm{C}$ for $30 \mathrm{~s}$, annealing at $52^{\circ} \mathrm{C}$ for $1 \mathrm{~min}$ and extension at $72^{\circ} \mathrm{C}$ for $1 \mathrm{~min}$, and then the final extension at $72^{\circ} \mathrm{C}$ for $5 \mathrm{~min}$ [32]. For each reaction, control positive (C. burnetii culture) and control negative (without DNA) were used. PCR products were analyzed on $1.5 \%$ agarose gel electrophorese with ethidium bromide, and they were visualized by Lab Image software (BIO-RAD, Singapore).

Table-1: The primers used for PCR and sequencing.

\begin{tabular}{llc}
\hline $\begin{array}{l}\text { Primer } \\
\text { name }\end{array}$ & Primer sequences & References \\
\hline Trans gene & \\
Trans1 & $5^{\prime}$-TATGTATCCACCGTAGCCAGT C-3' & [25] \\
Trans2 & 5'-CCCAACAACACCTCCTTATTC-3' $^{\prime}$ & \\
CB gene & & \\
CB1 & 5'-ACTCAACGCACTGGAACCGC-3' & [32] \\
CB2 & 5'-TAGCTGAAGCCAATTCGCC-3' & \\
\hline
\end{tabular}


Sequencing of PCR products

For PCR product purification, GeneJET Gel Extraction kit (Thermo Fisher Scientific, USA) was used according to the manufacturer's prescription. The sequencing was conducted using an ABI PRISM $^{\circledR}$ BigDye $^{\mathrm{TM}}$ terminator cycle sequencing kits with AmpliTaq ${ }^{\circledR}$ DNA polymerase (FS enzyme; Applied Biosystems), following the protocols supplied by the manufacturer. The obtained sequences were assembled and edited by ChromasPro software (ChromasPro 1.7, Technelysium Pty Ltd., Tewantin, Australia) and the corrected sequences were compared with those available in GenBank by BLAST (https://blast.ncbi.nlm.nih.gov/Blast.cgi).

\section{Serological studies (detection of $C$. burnetii IgG by ELISA)}

Due to the unavailability of species-specific diagnostic reagents, we used sheep $C$. burnetii ELISA kit (GSCIENCE, USA) for the detection of anti-C. burnetii IgG antibodies in accordance with the previous studies [11]. ELISA was performed on serum samples following the manufacturer's recommendations.

\section{Results}

Out of 112 male camels examined, 19 were positive for $C$. burnetii by qPCR (Figure-1) with an overall prevalence of $16.9 \%$ (18.6\% and $15.1 \%$ in Giza and Cairo Provinces, respectively; Table-2). All positive cases were apparently healthy with age range of 10-23 years old.
Standard PCR followed by sequencing based on $\mathrm{CB} 1$ and $\mathrm{CB} 2$ gene identified only two samples as $C$. burnetii. The obtained band of positive samples was around $250 \mathrm{bp}$ in length (Figure-2). Unfortunately, trails for sequencing positive PCR samples revealed poor sequencing.

Only 5 animals $(4.5 \%)$ were seropositive for anti-C. burnetii $\operatorname{IgG}$ antibodies. The seropositive cases were among the group selected at Giza Province slaughterhouse (Table-2).

\section{Discussion}

Q fever/coxiellosis is an emerging worldwide arthropozoonosis. Increased awareness of $\mathrm{Q}$ fever has been developed recently due to raised frequency of reported outbreaks and economic impact of the disease resulting from loss of animal productivity and herd death $[33,34]$. Therefore, the estimation of C. burnetii prevalence is important to understand the epidemiological status of this disease.

In Egypt, Q fever was reported serologically for the $1^{\text {st }}$ time in 1995 within a risk group of cattle keepers [35]. Later, several studies confirmed the prevalence of the disease in sheep, goat, and cattle livestock [18,20,21,36-38]. However, reports concerning the prevalence and incidence of $C$. burnetii in wild animals, particularly camels, are scarce.

The current study identified $C$. burnetii in dromedary camels using PCR and estimated its seroprevalence using ELISA. Our results revealed that C. burnetii was directly identified from whole blood

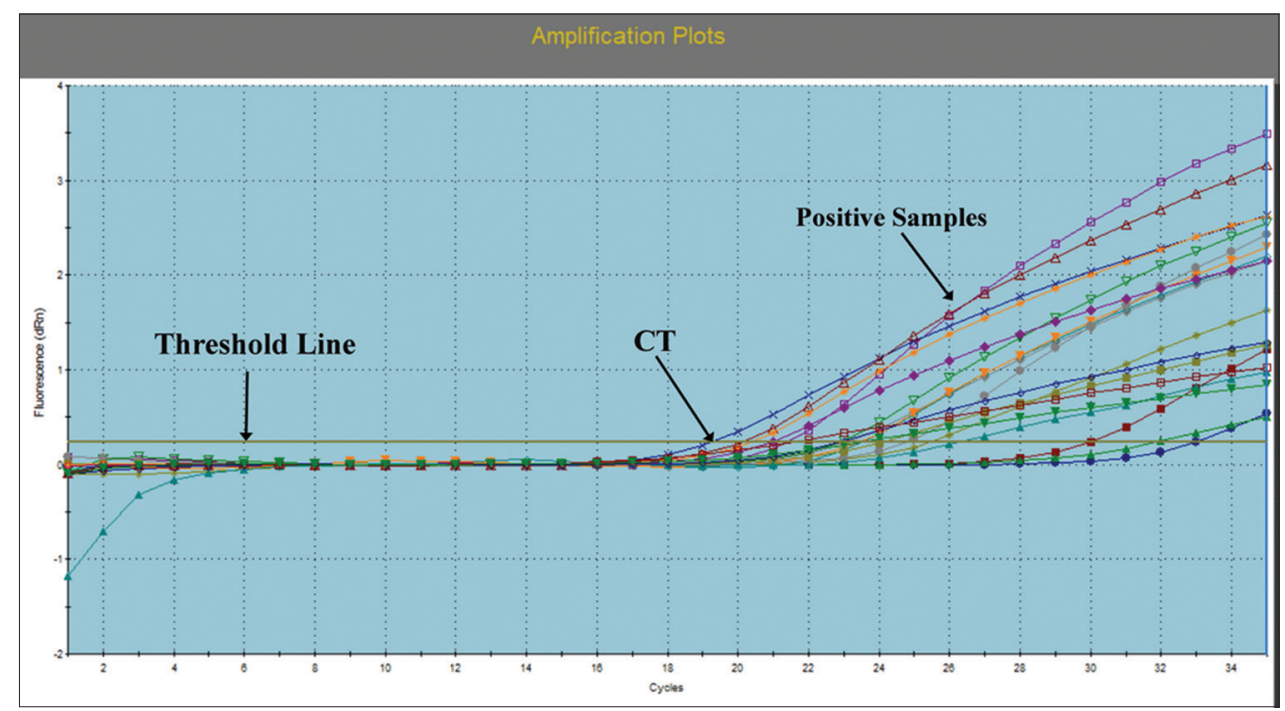

Figure-1: Amplification plots of suspected Coxiella burnetii using SYBR Green-based quantitative polymerase chain reaction.

Table-2: The prevalence of Q fever in the studied camels.

\begin{tabular}{lcccccc}
\hline \multirow{2}{*}{ Provinces } & \multirow{2}{*}{ Number of examined animals } & \multicolumn{2}{c}{ qPCR-positive camels } & & \multicolumn{2}{c}{ ELISA-positive camels } \\
\cline { 3 - 3 } & & No. & Prevalence (\%) & & No. & Prevalence (\%) \\
\hline Cairo & 53 & 8 & 15.1 & & 0 & 0 \\
Giza & 59 & 11 & 18.6 & & 5 & 8.4 \\
Total & 112 & 19 & 16.9 & & 5 & 4.5 \\
\hline
\end{tabular}

ELISA=Enzyme-linked immunosorbent assay, qPCR=Quantitative polymerase chain reaction 


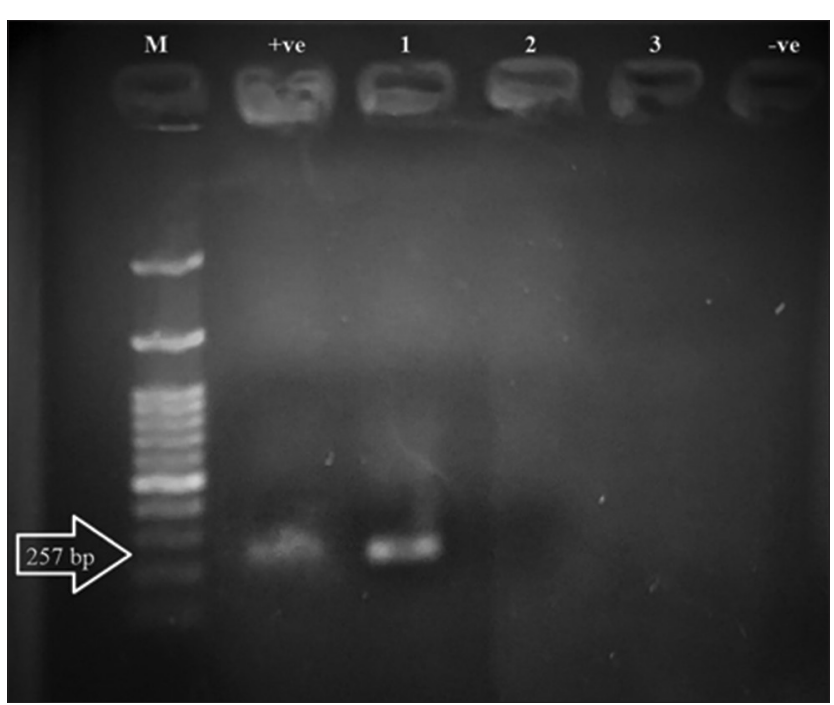

Figure-2: A 1.5\% agarose gel electrophoresis of Coxiella burnetii polymerase chain reaction using CB1 and CB2 gene. Lane M: 100 bp DNA ladder, lane +ve: control positive, lane -ve: control negative, lane 1 presents 250 bp amplicon of $C$. burnetii positive sample, while lanes 2 and 3 present $C$. burnetii negative samples.

by qPCR in 19 male camels with $16.9 \%$ infection rate. This result was in accordance with Mazyad and Hafez [18] who observed C. burnetii in $13 \%$ of examined camels in Egypt. Comparable results were reported by other studies from Kenya [12], Saudi Arabia [15], Spain [16], and Iran [39] who estimated the prevalence of $C$. burnetii was $18.6,15.8,19$, and $10.8 \%$, respectively. However, several earlier reports from Egypt [19-22], Chad [40], and Kenya [11] displayed much higher prevalence rates; ranging from $40.7 \%$ to $73 \%$. This variance with our result may be due to either difference in geographical and environmental conditions between Egypt and other countries or variations in the sensitivity of laboratory tools. The infected camels in the present study were native breed and appeared clinically healthy at the time of examination, which might be attributed to tolerance developed by the Egyptian camel breed against this disease. Accordingly, camel plays a critical role as reservoir of C. burnetii in Egypt.

While qPCR detected C. burnetii DNA in camel blood in $16.9 \%$ of cases, standard PCR succeeded in amplifying only two samples and failed in sequencing the obtained PCR products. Such results may be clarified by that $C$. burnetii prevalence in blood and milk is lower than faces and urine $[15,41]$. On the other hand, conventional PCR showed many disadvantages. It is time-consuming, it did not offer quantitative data, and conventional primers showed lack of specificity [42]. Hence, we concluded that qPCR targeting trans-region of $C$. burnetii genome was faster, more sensitive, and valuable than the other primers. This agrees with Costa et al. [43] who elucidated that quantitative reverse transcription-PCR (qRT-PCR) can correlate the quantity of DNA with clinical symptoms, and it can be used to follow up treatment and monitor its efficacy. Edvinsson et al. [44] demonstrated that qRT-PCR can detect low concentrations of DNA. In our study, the specificity of qRT-PCR was $100 \%$, and it is considered an excellent test.

In this study, we detected IgG antibodies against C. burnetii in 5 camels (4.5\%) sampled at Giza Province slaughterhouse. This is comparable to an earlier study in the United Arab Emirates that detected a nearby infection rate $(7.9 \%)$ in camels [45]. The presence of IgG antibodies in ELISA-positive camels indicated exposure to C. burnetii in the past and the possibility of chronically harboring the infection by the animals. Consequently, camels may be playing a role in the maintenance of infection in nature.

\section{Conclusion}

Trans-qPCR assay is a rapid, specific, sensitive, automated, and quantitative way of detecting C. burnetii infection, especially in early stage. Camels may be playing a critical role in transmission of Q fever to humans in Egypt. Disease awareness between veterinarians, physicians, and camel owners should be raised. Understanding the epidemiology of Q fever and its impact on humans' health and on the Egyptian economy is of paramount importance. Further research should elucidate further the camels' role in the transmission of $C$. burnetii to humans and the potential risk factors for exposure.

\section{Authors' Contributions}

HHAMA, HAH, KAA, AMAB, and YAS participated in the design of the study. HHAMA collected blood samples from camels and sera separation. HHAMA, HAH, and YAS participated in conducting st. PCR and qPCR. HAH, HHAMA, $\mathrm{AMAB}$, and KAA participated in ELISA techniques. HHAMA wrote the first draft of the manuscript. All authors reviewed and approved the final manuscript.

\section{Acknowledgments}

The authors are thankful to the Police Academy, Cairo and Giza provinces, Egypt and General Organization for Veterinary Services, Giza province, Egypt for facilitating the samples collection. The authors did not receive any funds for this study.

\section{Competing Interests}

The authors declare that they have no competing interests.

\section{Publisher's Note}

Veterinary World remains neutral with regard to jurisdictional claims in published institutional affiliation.

\section{References}

1. Njeru, J., Henning, K., Pletz, M.W., Heller, R. and Neubauer, H. (2016) Q fever is an old and neglected zoonotic disease in Kenya: A systematic review. BMC Public Health, 16(1): 297-304.

2. Voth, D.E. and Heinzen, R.A. (2007) Lounging in a 
lysosome: The intracellular lifestyle of Coxiella burnetii. Cell Microbiol., 9(4): 829-840.

3. Eldin, C., Mélenotte, C., Mediannikov, O., Ghigo, E., Million, M., Edouard, S., Mege, J.L., Maurin, M. and Raoult, D. (2017) From Q fever to Coxiella burnetii infection: A paradigm change. Clin. Microbiol. Rev., 30(1): 115-190.

4. Guatteo, R., Seegers, H., Taurel, A.F., Joly, A. and Beaudeau, F. (2011) Prevalence of Coxiella burnetii infection in domestic ruminants: A critical review. Vet. Microbiol., 149(1-2): 1-16.

5. Hartzell, J.D., Wood-Morris, R.N., Martinez, L.J. and Trotta, R.F. (2008) Q fever: Epidemiology, diagnosis, and treatment. Mayo Clin. Proc., 83(5): 574-579.

6. Maurin, M. and Raoult, D. (1999) Q fever. Clin. Microbiol. Rev., 12(4): 518-553.

7. Kersh, G.J., Fitzpatrick, K.A., Self, J.S., Priestley, R.A., Kelly, A.J., Lash, R.R., Marsden-Haug, N., Nett, R.J., Bjork, A., Massung, R.F. and Anderson, A.D. (2013) Presence and persistence of Coxiella burnetii in the environments of goat farms associated with a $\mathrm{Q}$ fever outbreak. Appl. Environ. Microbiol., 79(5): 1697-1703.

8. Salifu, S.P., Bukari, A.A., Frangoulidis, D. and Wheelhouse, N. (2019) Current perspectives on the transmission of Q fever: Highlighting the need for a systematic molecular approach for a neglected disease in Africa. Acta Trop., 193(5): 99-105.

9. Raoult, D., Marrie, T. and Mege, J. (2005) Natural history and pathophysiology of Q fever. Lancet Infect. Dis., 5(4): 219-226.

10. Wernery, U., Kinne, J. and Schuster, R.K. (2014) Camelid Infectious Disorders. OIE, World Organization for Animal Health, Paris.

11. DePuy, W., Benka, V., Massey, A., Deem, S.L., Kinnaird, M., O’Brien, T., Wanyoike, S., Njoka, J., Butt, B., Foufopoulos, J., Eisenberg, J.N. and Hardin, R. (2014) Q fever risk across a dynamic, heterogeneous landscape in Laikipia County, Kenya. Ecohealth, 11(3): 429-433.

12. Browne, A.S., Fèvre, E.M., Kinnaird, M., Muloi, D.M., Wang, C.A., Larsen, P.S., O'Brien, T. and Deem, S.L. (2017) Serosurvey of Coxiella burnetii (Q fever) in dromedary camels (Camelus dromedarius) in Laikipia County, Kenya. Zoonoses Public Health, 64(7): 543-549.

13. Janati-Pirouz,H., Mohammadi, G., Mehrzad, J.,Azizzadeh, M., Nazem-Shirazi, M.H. (2015) Seroepidemiology of Q fever in one-humped camel population in Northeast Iran. Trop. Anim. Health Prod., 47(7): 1293-1308.

14. Mohabbati, M.A., Bagheri, A.F. and Esmaeili, S. (2017) Seroprevalence of Q fever among human and animal in Iran; A systematic review and meta-analysis. PLoS Negl. Trop. Dis., 11(4): e0005521.

15. Hussein, M.F., Alshaikh, M.A., Al-Jumaah, R.S., GarelNabi, A., Al-Khalifa, I. and Mohammed, O.B. (2015) The Arabian camel (Camelus dromedarius) as a major reservoir of Q fever in Saudi Arabia. Comp. Clin. Path., 24(4): 887-892.

16. Mentaberre, G., Gutiérrez, C., Rodríguez, N.F., Joseph, S., González-Barrio, D., Cabezón, O., de la Fuente, J., Gortazar, C. and Boadella, M.A. (2013) Transversal study on antibodies against selected pathogens in dromedary camels in the Canary Islands, Spain. Vet. Microbiol., 167(3-4): 468-473.

17. Khalafalla, A.I., Al Eknah, M.M., Abdelaziz, M. and Ghoneim, I.M. (2017) A study on some reproductive disorders in dromedary camel herds in Saudi Arabia with special references to uterine infections and abortion. Trop. Anim. Health Prod., 49(5): 967-974.

18. Mazyad, S.A. and Hafez, A.O. (2007) Q fever (Coxiella burnetii) among man and farm animals in North Sinai, Egypt. J. Egypt. Soc. Parasitol., 37(1): 135-142.

19. Soliman, A.K., Botros, B.A.M. and Watts, D.M. (1992) Evaluation of a competitive enzyme immunoassay for detection of Coxiella burnetii antibody in animal sera. $J$. Clin. Microbiol., 30(6): 1595-1597.

20. Horton, K.C., Wasfy, M., Samaha, H., Abdel-Rahman, B., Safwat, S., Fadeel, M.A., Mohareb, E. and Dueger, E.
(2014) Serosurvey for zoonotic viral and bacterial pathogens among slaughtered livestock in Egypt. Vector Borne Zoonotic Dis., 14(9): 633-639.

21. Klemmer, J., Njeru, J., Emam, A., El-Sayed, A., Moawad, A.A., Henning, K., Elbeskawy, A.M., Sauter-Louis, C., Straubinger, K.R., Neubauer, H. and El-Diasty, M.M. (2018) Q fever in Egypt: Epidemiological survey of Coxiella burnetii specific antibodies in cattle, buffaloes, sheep, goats and camels. PLoS One, 13(2): e0192188.

22. Abdullah, H.H.A., El-Shanawany, E.E., Abdel-Shafy, S., Abou-Zeina, H.A.A. and Abdel-Rahman, E.H. (2018) Molecular and immunological characterization of Hyalomma dromedarii and Hyalomma excavatum (Acari: Ixodidae) vectors of Q fever in camels. Vet. World, 11(8): 1109-1119.

23. Fournier, P.E., Marrie, T.J. and Raoult, D. (1998) Diagnosis of Q fever. J. Clin. Microbiol., 36(7): 1823-1834.

24. Arricau-Bouvery, N. and Rodolakis, A. (2005) Is Q fever an emerging or re-emerging zoonosis? Vet. Res., 36(3): 327-349.

25. Berri, M., Laroucau, K. and Rodolakis, A. (2000) The detection of Coxiella burnetii from ovine genital swabs, milk and fecal samples by the use of a single touchdown polymerase chain reaction. Vet. Microbiol., 72(3-4): 285-293.

26. Peter, O., Dupuis, G., Bee, D., Luthy, R., Nicolet, J. and Burgdorfer, W. (1988) Enzyme-linked immunosorbent assay for diagnosis of chronic Q fever. J. Clin. Microbiol., 26(10): 1978-1982.

27. Cowley, R., Fernandez, F., Freemantle, W. and Rutter, D. (1992) Enzyme immunoassay for Q fever: Comparison with complement fixation and immunofluorescence tests and dot immunoblotting. J. Clin. Microbiol., 30(9): 2451-2455.

28. Rahimi, E., Doosti, A., Ameri, M., Kabiri, E. and Sharifian, B. (2010) Detection of Coxiella burnetii by nested PCR in bulk milk samples from dairy bovine, ovine, and caprine herds in Iran. Zoonoses Public Health, 57(7-8): 38-41.

29. Szymańska-Czerwińska, M., Galińska, E.M., Niemczuk, K. and Knap, J.P. (2015) Prevalence of Coxiella burnetii infection in humans occupationally exposed to animals in Poland. Vector Borne Zoonotic Dis., 15(4): 261-267.

30. Khanzadi, S., Jamshidi, A., Razmyar, J. and Borji, S. (2014) Identification of Coxiella burnetii by touch-down PCR assay in unpasteurized milk and dairy products in North East of Iran. Iran. J. Vet. Med., 8(1): 15-19.

31. Vaidya, V.M., Malik, S.V., Kaur, S., Kumar, S. and Barbuddhe, S.B. (2008) Comparison of PCR, immunofluorescence assay and pathogen isolation for diagnosis of Q fever in humans with spontaneous abortions. J. Clin. Microbiol., 46(6): 2038-2044.

32. Stein, A. and Raoult, D. (1992) Detection of Coxiella burnetii by DNA amplification using polymerase chain reaction. J. Clin. Microbiol., 30(9): 2462-2466.

33. Amitai, Z., Bromberg, M., Bernstein, M., Raveh, D., Keysary, A., David, D., Pitlik, S., Swerdlow, D., Massung, R., Rzotkiewicz, S., Halutz, O. and Shohat, T. (2010) A large Q fever outbreak in an urban school in central Israel. Clin. Infect. Dis., 50(11): 1433-1438.

34. Enserink, M. (2010) Questions abound in Q fever explosion in the Netherlands. Science, 327(5963): 266-267.

35. Botros, B.A., Soliman, A.K., Salib, A.W., Olsen, J., Hibbs, R.G., Williams, J.C., Darwish, M., El-Tegani, A. and Watts, D. (1995) Coxiella burnetii antibody prevalence in North-East Africa determined by enzyme immunoassay. $J$. Trop. Med. Hyg., 98(3): 173-178.

36. Gwida, M., El-Ashker, M., El-Diasty, M., Engelhardt, C., Khan, I. and Neubauer, H. (2014) Q fever in cattle in some Egyptian governorates: A preliminary study. BMC Res. Notes, 7(12): 881 .

37. Khalifa, O.N., Elhofy, I.F., Fahmy, A.H., Mona, M., Sobhy, M.M. and Agag, M.A. (2016) Seroprevalence and molecular detection of Coxiella burnetii infection in sheep, goats and human in Egypt. ISOI J. Microbiol. Biotechnol. Food Sci., 2(1): 1-7.

38. Abdel-Moein, K.A. and Hamza, D.A. (2017) The burden of 
Coxiella burnetii among aborted dairy animals in Egypt and its public health implications. Acta Trop., 166(2): 92-95.

39. Doosti, A., Arshi, A. and Sadeghi, M. (2014) Investigation of Coxiella burnetii in Iranian camels. Comp. Clin. Path., 23(1): 43-46.

40. Schelling, E., Diguimbaye, C., Daoud, S., Nicolet, J. and Zinsstag, J. (2004) Seroprevalences of zoonotic diseases in nomads and their livestock in Chari-Baguirmi, Chad. Méd. Trop (Mars), 64(5): 474-477.

41. Mohammed, O.B., Jarelnabi, A.A., Aljumaah, R.S., Alshaikh, M.A., Bakhiet, A.O., Omer, S.A., Alagaili, A.N. and Hussein, M.F. (2014) Coxiella burnetii, the causative agent of Q fever in Saudi Arabia: Molecular detection from camel and other domestic livestock. Asian Pac. J. Trop. Med., 7(9): 715-719.

42. Kompalic-Cristo, A., Nogueira, S.A., Guedes, A.L.,
Frota, C., González, L.F., Brandão, A., Amendoeira, M.R., Britto, C. and Fernandes, O. (2004) Lack of technical specificity in the molecular diagnosis of toxoplasmosis. Trans. R. Soc. Trop. Med. Hyg., 98(2): 92-95.

43. Costa, J.M., Pautas, C., Ernault, P., Foulet, F., Cordonnier, C. and Bretagne, S. (2000) Real-time PCR for diagnosis and follow-up of toxoplasma reactivation after allogeneic stem cell transplantation using fluorescence resonance energy transfer hybridization probes. J. Clin. Microbiol., 38(8): 2929-2932.

44. Edvinsson, B., Lappalainen, M. and Evenga, B. (2005) Realtime PCR targeting a 529-bp repeat element for diagnosis of toxoplasmosis. Clin. Microbiol. Infect., 12(2): 131-136.

45. Afzal, M. and Sakkir, M. (1994) Survey of antibodies against various infectious disease agents in racing camels in Abu Dhabi, United Arab Emirates. Rev. Sci. Tech., 13(3): 787-792.

$* * * * * * * *$ 